\title{
Crítica genética, um método para o estudo da produção do acontecimento jornalístico ${ }^{1}$
}

\begin{abstract}
RESUMO
Este paper tem o objetivo de refletir sobre a Crítica Genética como uma alternativa metódica para o estudo da produção da biografia como acontecimento jornalístico. Para isso, primeiramente, circunscreve-se o gênero à condição de acontecimento e, a seguir, discute-se a biografia no jornalismo. Na segunda parte, apresenta-se a Crítica Genética e aplica-se a metodologia para a análise da produção do Prólogo da biografia Padre Cícero: poder, fé e guerra no sertão, de autoria do jornalista Lira Neto.
\end{abstract}

\section{PALAVRAS-CHAVE}

Acontecimento

Biografia

Jornalismo

\begin{abstract}
This paper aims to offer some reflexions on the Genetical Review as a methodological alternative to the study of the production of biographies as a journalistic event. Being such the purpose, the genre is, first thing, given the condition of event and then, next, there is some discussion on the role biographies play in journalism. In the second part, the Genetical Review is presented, and a methodology is also presented for the analysis of production of the Prologue of Father Cícero: power, faith and war in the outback, a biography written by the journalist Lira Neto.
\end{abstract}

\section{KEYWORDS}

Event

Biography

Journalism

\section{Virginia Pradelina da Silveira Fonseca}

Professora do Programa de Pós-Graduação em Comunicação e Informação da UFRGS/RS/BR. virginia@ufrgs.br

\section{Karine Moura Vieira}

Mestranda do Programa de Pós-Graduação em Comunicação e Informação da UFRGS/RS/BR. karinemourav@terra.com.br 


\section{Este paper tem o objetivo de refletir sobre} a Crítica Genética como uma das alternativas possíveis para o estudo da produção da biografia como acontecimento jornalístico. Para a sua consecução, divide-se o texto em duas partes. Na primeira, circunscreve-se o gênero à condição de acontecimento, fazendo-se uma revisão bibliográfica com a finalidade de definir conceitualmente e de estabelecer a relação entre biografia e acontecimento jornalístico. Na segunda parte, apresenta-se a Crítica Genética, pouco conhecida e aplicada nos estudos do jornalismo, e, por fim, procura-se aplicar a metodologia na análise do Prólogo do livro Padre Cícero: poder, fé e guerra no sertão, escrito pelo jornalista Lira Neto.

\section{A biografia como acontecimento}

Assim como um fato, como a queda de um avião, uma declaração de pessoa pública, seja ela uma autoridade ou uma personalidade do mundo artístico ou dos negócios, ou um número ou percentagem, sobre o crescimento do Produto Interno Bruto em determinado período, por exemplo, também a vida de uma personagem, conhecida ou anônima, pode vir a se transformar num acontecimento jornalístico. E poderá ascender a essa condição de diversas formas numa entrevista, numa reportagem, num perfil ou numa biografia -, desde que a vida dessa personagem seja apreensível pela instituição jornalística como relevante e significativa para a compreensão de parte da realidade.

\section{0 acontecimento nasce, vive e morre numa dialética permanente da ordem e da desordem, dialética que pode estar na natureza, mas cuja percepção e significância dependem de um sujeito que interpreta o mundo.}

A biografia constitui um acontecimento jornalístico porque é uma construção de sentido que se situa no âmbito do "mundo a comentar", identificado por Charaudeau (2007) como pertencente à esfera da produção. Isto quer dizer que a biografia jornalística, tal como qualquer outro fato, é uma fenomenalidade que não se impõe à recepção em estado bruto, mas depois de passar pelo olhar de um sujeito - o jornalista - que o integra num sistema de pensamento e, assim, o torna inteligível, quando passa a integrar o "mundo comentado".
Muitos autores não distinguem entre acontecimento e fato, e quando o fazem é para dizer, como Mouillaud (1997, p. 51), que "o acontecimento é a sombra projetada de um conceito construído pelo sistema da informação, o conceito de fato"; ou, como Sodré (2009), que, à semelhança do primeiro, diz que, na prática, o acontecimento pode ser tomado como sinônimo de fato sóciohistórico.

Visando circunscrever a notícia ao conceito de acontecimento, por exemplo, o autor recorre à imagem de "sombra projetada", de Mouillaud (1997), para dizer que esta responde a critérios como singularidade, acidentalidade, improbabilidade, unicidade, desvio, pregnância, etc., e que estes seriam critérios que supõem a atenção ou a percepção de um público. Para Sodré (2009), não existe acontecimento sem "sujeitos de percepção". O exemplo a seguir é esclarecedor:

[...] é um fato bruto que existe uma grande estátua do Cristo Redentor no topo do morro conhecido como Corcovado, na cidade do Rio de Janeiro. Mas como ou por que aquela estátua foi ali colocada, ou então a sua escolha como uma das maravilhas do mundo são casos potencialmente informativos. A informação jornalística parte de objetos primariamente tidos como factuais, para obter, por intermédio do acontecimento, alguma clareza sobre o fato sócio-histórico (Sodré, 2009, p. 32).

Na mesma perspectiva, Charaudeau também explicará que o acontecimento nasce, vive e morre numa dialética permanente da ordem e da desordem, dialética que pode estar na natureza, mas cuja percepção e significância dependem de um sujeito que interpreta o mundo:

Mortos são mortos, mas para que signifiquem 'genocídio', 'purificação étnica', 'solução final', 'vítimas do destino', é preciso que se insiram em discursos de inteligibilidade do mundo que apontam para sistemas de valores que caracterizam os grupos sociais. Ou seja, para que o acontecimento exista é necessário nomeá-lo (Charaudeau, 2007, p. 131).

Neste texto, leva-se em conta essa problematização conceitual e compartilha-se com Rodrigues (1993) a concepção de que acontecimento é tudo o que irrompe na superfície lisa da história, entre uma multiplicidade aleatória de fatos virtuais. A biografia, portanto, constitui 
um acontecimento jornalístico à medida que se pode compreender fato como a ocorrência, "manifestação da ordem da realidade", e acontecimento, como "o modo como essa ocorrência é apreendida pelo sujeito" (Guerra, 2008, p. 36). Neste caso, o fato é a vida do biografado, e o acontecimento, a narrativa dessa vida na forma de uma grande reportagem.

\section{A biografia no jornalismo}

A biografia é um gênero interdisciplinar, que se situa entre as fronteiras de um campo formado pela história, pela literatura e pelo jornalismo. Biografar significa, grosso modo, escrever vidas. "Em rigor é a compilação de uma (ou várias) vida(s)" (Vilas Boas, 2002, p. 18). Pode ser impressa em papel, mas outros meios, como cinema, televisão e o teatro também podem acolhê-la. Ou seja, é uma narrativa. Nesse sentido, é um recorte, uma interpretação, de forma que não existe "a", mas "uma" biografia ${ }^{2}$. Distinguese da história de vida e do perfil ${ }^{3}$ por ser mais detalhada, mais ampla, mais atenta para facetas, episódios, para os convivas, os legados e os feitos, entre outros aspectos, da vida do biografado.

A história é o berço da biografia, embora tenha sido vista por esta como literatura. Já a literatura foi seduzida pelo gênero graças às suas possibilidades como forma de expressão artística e, ao mesmo tempo, por sua capacidade de atribuir sentido de verdade a um relato.

$\mathrm{Na}$ ciência historiográfica foi vista com reservas ${ }^{4}$ por conta da sua subjetividade, mas foi adquirindo importância a partir da renovação que se operou no campo "com o declínio [...] das teorias e dos saberes sobre os quais a história havia ancorado seus avanços nos anos sessenta e setenta" (Motta, 2000, p. 6). A partir desse período, opera-se uma volta para o particular para compreender a história total, e o indivíduo passa a ser visto como protagonista. Nesse contexto, a subjetividade antes tida como problema, adquire valor de objeto com a utilização das várias formas de história oral na formação de fontes.

$\mathrm{Na}$ literatura, o factual da vida se encontra com o ficcional da obra literária, e muitos foram os escritores que se aventuraram no gênero. Nesse campo, ao contrário do que acontecera na história, a subjetividade não era um problema, e as implicações do ato de biografar eram outras. Seu hibridismo é entendido como característica a ser aceita e trabalhada visando à excelência do gênero. Assim como na história, entretanto, foi ganhando contornos diferentes ao longo do tempo ${ }^{5}$. No jornalismo, institui-se a partir das contribuições desses e de outros campos, como a sociologia e a antropologia. A história empresta o seu instrumental de reconstituição do passado; a literatura, as suas técnicas narrativas. Assim, combinam-se recursos e conceitos de várias áreas.

Nos últimos anos, muitos jornalistas vêm se dedicando ao fazer biográfico. As biografias jornalísticas, escritas por profissionais que as produzem com estratégias e técnicas próprias da profissão, geralmente são publicadas na forma de livro-reportagem, uma espécie de "veículo jornalístico" não periódico que trata a informação de maneira mais aprofundada que as tradicionais mídias impressas - jornais e revistas. Segundo Lima (1993), a biografia seria um tipo de livroreportagem, que pode ser classificado em várias outras categorias ${ }^{6}$. Assim, como qualquer das formas constitutivas dos gêneros jornalísticos (informação e opinião ${ }^{7}$ ou relatos e comentários ${ }^{8}$ ), é resultado da elaboração de uma pauta, de uma apuração, seleção e edição'.

Tomando como critério os contratos autorais, Vilas Boas (2002) classifica as biografias em: autorizadas (quando aprovadas pelo biografado ou por sua família), não-autorizadas (quando o biógrafo investiga por conta própria e sem o consentimento do biografado ou de seus familiares), encomendadas (por editores, pelo biografado ou por seus familiares) e ditadas (quando o biógrafo exerce o papel de gostwriter, isto é, escreve em nome de alguém, da personagem central).

Um dos primeiros exercícios de escrita biográfica que ajudou a constituir o gênero no país, pelo jornalismo, foi o livro Morte no Paraíso (1981), de Alberto Dines, sobre Stefan Zweig. Na sua esteira, ainda na década de 1980, Fernando Morais lançou Olga (1985) - sobre Olga Benário Prestes, lendária militante alemã do Partido Comunista e mulher do líder comunista brasileiro Luis Carlos Prestes, que foi presa durante o Estado Novo e entregue aos nazistas pela polícia de Getúlio Vargas, vindo a morrer num campo de concentração na Alemanha. Quase dez anos depois, Morais consolidou sua condição de biógrafo em Chatô - O rei do Brasil (1994), sobre o empresário Assis Chateaubriand, fundador do grupo Diários e Emissoras Associados. Sua mais recente investida foi O Mago (2008), sobre 
o escritor Paulo Coelho - a primeira biografia escrita por ele de um personagem vivo.

Sujeitos do seu tempo, esses personagens, ao terem suas existências resgatadas pelos biógrafos, são apresentados com um novo significado, não como uma reinvenção da sua existência, mas com outra possibilidade de entendimento e registro de memória e de valor da sua trajetória.

Com uma trajetória de sucesso semelhante, Ruy Castro firmou-se como biógrafo pelas produções de O Anjo Pornográfico (1992), sobre o escritor e dramaturgo Nelson Rodrigues, $A$ Estrela Solitária (1995), sobre o jogador de futebol Garrincha, e também com Carmem (2005), sobre Carmem Miranda, ícone da música popular brasileira.

Atualmente, muitos outros jornalistas vêm procurando na biografia uma nova vertente para o exercício da reportagem de fôlego, buscando desvendar as trajetórias de vida de personagens que fazem parte do imaginário coletivo, seja nas artes, na política, vultos que já foram até investigados em outras obras, mas que pela multiplicidade de facetas de sua existência, permitem uma nova busca. Sujeitos do seu tempo, esses personagens, ao terem suas existências resgatadas pelos biógrafos, são apresentados com um novo significado, não como uma reinvenção da sua existência, mas com outra possibilidade de entendimento e registro de memória e de valor da sua trajetória.

Algumas biografias trouxeram à história dos biografados um revival do seu legado, como no caso do livro Maysa - Só numa multidão de amores (2007), do jornalista Lira Neto sobre a cantora Maysa Matarazzo. A obra serviu de base para a minissérie homônima produzida pela Rede Globo e exibida em 2009, e despertou o interesse da indústria cultural, que fez o relançamento de discos e regravações de suas composições. O mais recente trabalho de Lira Neto é sobre o Padre Cícero, popular mito religioso do nordeste brasileiro. No livro Padre Cícero - Poder, fé e guerra no sertão, lançado em novembro de 2009, o jornalista narra a trajetória dessa personagem mítica que atrai milhares de devotos em peregrinação, anualmente, a Juazeiro do Norte, no Sertão do Cariri (Ceará). A biografia chegou ao mercado no momento em que o Vaticano, 75 anos depois da morte do líder religioso, decidiu discutir a sua reabilitação.

Como, no entanto, se faz uma biografia? Quais os recursos, fontes de informação e técnicas utilizadas por um jornalista para a produção da narrativa de uma vida, conferindo-lhe assim o caráter de acontecimento? Descrever e analisar o making-off da produção biográfica é o nosso objetivo neste texto. Para isso, faz-se um exercício com o Prólogo da mais recente obra de Lira Neto. E para a sua consecução elege-se a Crítica Genética como metodologia de investigação.

\section{Crítica Genética, a ciência dos caminhos percorridos}

Com origens nas artes e na literatura, a Crítica Genética, a ciência dos manuscritos, é uma perspectiva teórico-metodológica ${ }^{10}$ pouco conhecida e aplicada nos estudos do jornalismo. "Seu objeto: os manuscritos literários, tidos como portadores do traço de uma dinâmica, a do texto em criação. Seu método: o desnudamento do corpo e do processo da escrita, acompanhado da construção de uma série de hipóteses sobre as operações escriturais. Sua intenção: a literatura como um fazer, como atividade, como movimento" (Grésillon, 2007, p. 19).

Como é criada uma obra? Segundo Salles (2008), essa é a grande questão de pesquisa da Crítica Genética, que analisa os documentos dos processos criativos com a finalidade de compreender, no próprio movimento da criação, os procedimentos de produção e, assim, entender o processo que presidiu o desenvolvimento da obra.

Ao investigar a obra em seu vir-a-ser, o crítico genético se detém, muitas vezes, na contemplação do provisório. Ele reintegra os documentos preservados e conservados - um objeto, aparentemente, parado no tempo - no fluxo da vida. Ele tem, na verdade, a função de devolver à vida a documentação, na medida em que essa sai dos arquivos ou das gavetas e retorna à vida ativa como processo: um pensamento em evolução, idéias crescendo em formas que vão se aperfeiçoando, um artista em ação, uma criação em processo (Salles, 2008, p. 29).

Essa forma de olhar, nas palavras de um dos seus fundadores, implica senão uma escolha, no mínimo preferências: 
As da produção sobre o produto, da escritura sobre o escrito, da textualização sobre o texto, do múltiplo sobre o único, do possível sobre o finito, do virtual sobre o ne varietur, do dinâmico sobre o estático, da operação sobre o opus, da gênese sobre a estrutura, da enunciação sobre o enunciado, da força da escrita sobre a forma do impresso (Gréssilon, 2007, p. 19).

Conforme Salles, a Crítica Genética surgiu com o desejo de melhor compreender o processo de criação artística, a partir dos registros de percurso deixados pelo artista, mas não se fundamenta em objeto que lhe seja próprio. $\mathrm{O}$ estudo do manuscrito literário seria bastante antigo, assim como os estudos dos esboços da pintura ou das partituras musicais, razão por que muitos outros pesquisadores dedicam-se também a esses objetos. Para a autora, porém, o que confere especificidade ao método, o que o distingue de outros estudos que também têm esses documentos como objeto, é o seu propósito - "é o fato de tomá-los como índices do processo de criação, suportes para a produção artística ou registros da memória de uma criação, e assim dar um tratamento metodológico que possibilite um maior conhecimento sobre esse percurso (Salles, 2008, p.30).

\section{É possível assegurar, contudo, que, vivendo os meandros da criação, quando em contato com a materialidade do processo, pode-se conhecê-la melhor.}

A autora lembra que, na medida em que se lida com os registros feitos pelo artista ao longo do percurso de construção de sua obra (os índices materiais do processo), podemos acompanhar seu trabalho contínuo e, assim, observar que o ato criador é resultante de um processo. "Sob essa perspectiva, a obra não é, mas vai se tornando, ao longo de um processo que envolve uma rede complexa de acontecimentos" (Salles, 2008, p. 25). Dessa forma, como poderemos conferir na análise do Prólogo da biografia do Pe. Cícero, escrita pelo jornalista Lira Neto, a obra é precedida por um complexo percurso, feito de pesquisas, ajustes, esboços, planos, materialidades, etc., que constituem os rastros deixados pelo biógrafo de seu percurso criador.

A Crítica Genética não tem acesso a todo o processo de criação, mas apenas a alguns de seus índices. É possível assegurar, contudo, que, vivendo os meandros da criação, quando em contato com a materialidade do processo, podese conhecê-la melhor, assegura-nos a autora, para quem o nome da metodologia se deve ao fato de que essas pesquisas se dedicam ao acompanhamento teórico-prático do processo da gênese das obras de arte. "Trata-se, na verdade, de uma outra possível abordagem para a arte, que caminha lado a lado com as críticas das obras, assim como são entregues ao público" (Salles, 2008, p. 27).

A preocupação em caracterizar o objeto de estudo leva-a a explicar que a Crítica Genética incorpora aos estudos da arte (e, por conseguinte, aos estudos das obras de caráter jornalístico) um objeto para além dos limites da obra como ela é entregue ao público: seu processo de criação.

Desse modo, acompanha esse percurso para desmontá-lo e, em seguida pô-lo em ação novamente, pois seu objeto de estudo é o caminho percorrido pelo artista para chegar (ou quase sempre chegar) às obras [...]. É, portanto, uma pesquisa baseada em documentos em processo, em oposição às pesquisas que se valem de produtos ditos acabados (Salles, 2008, p. 34-35).

Na seção a seguir, analisam-se os rastros deixados pelo jornalista Lira Neto no processo criativo que levou ao Prólogo da biografia Padre Cícero: poder, fé e guerra no sertão.

\section{Rastros da criação do Prólogo}

As cadernetas utilizadas pelo jornalista Lira Neto e os manuscritos da biografia Padre Cícero - poder, fé e guerra no sertãa, são os pontos de partida para a análise da gênese do Prólogo desta obra. Iniciou-se o trabalho pela leitura e pelo fichamento da caderneta que contém todos os apontamentos para a estruturação dessa parte do livro (o jornalista Lira Neto concentrou todas as anotações sobre o Prólogo em uma única caderneta). Ao longo desse processo, fizeram-se anotações sobre pontos a serem observados nos documentos a serem analisados posteriormente: três manuscritos, o texto final publicado e as fontes de informação (documentos e reportagens).

O segundo passo foi a identificação da ordem de produção dos manuscritos. Como esses documentos não estão identificados por data de criação, foi necessária a leitura de cada um dos textos para a identificação. Isso foi 
feito nos manuscritos identificados como "1" e "2", pois o definido como " 3 " tem a anotação "cópia lida por Luiz Schwarcz", sinalizando que foi lida pelo editor da editora Companhia das Letras, responsável pela leitura final dos manuscritos. Além disso, observou-se nessa cópia a complementação do processo de produção, com a inserção de dados e informações que estavam em aberto nas cópias " 1 " e " 2 ".

Depois da ordenação dos manuscritos, fez-se uma leitura orientada pelas anotações contidas na caderneta e o fichamento de cada um dos manuscritos. Nas fichas, registrou-se a trajetória do processo de produção, com a identificação dos esquemas desenvolvidos na caderneta.

A terceira etapa foi marcada pela leitura e pelo fichamento do texto final do Prólogo publicado no livro, processos também orientados pelas anotações da caderneta.

O último passo foi a leitura e identificação das fontes de informação utilizadas. Essas fontes estavam previamente identificadas pelo autor em um envelope que continha uma etiqueta com a anotação "reabilitação Cícero". No envelope, estavam as reportagens e documentos reunidos pelo autor sobre o processo de reabilitação do Padre Cícero pelo Vaticano.

As primeiras páginas do livro Padre Cicero poder, fé e guerra no sertão narram o começo de um dia na vida do então cardeal alemão Joseph Ratzinger, no ano de 2001, quatro anos antes de se tornar o papa Bento XVI. Naquele momento, o cardeal, na condição de prefeito da Congregação para a Doutrina da Fé, no Vaticano, dava início a uma nova fase na história do Padre Cícero na Igreja Católica, trabalhando na articulação do processo de reabilitação do sacerdote. Pe. Cícero se tornou santo pela canonização popular, arrebanhando milhões de fiéis todos os anos em gigantescas romarias a Juazeiro do Norte, no interior do Ceará, à revelia de sua excomunhão no final do século XIX. O fenômeno não passou despercebido pela Igreja Católica, principalmente em um momento em que se vê abalada pela perda de fiéis para as igrejas evangélicas em todo o mundo.

O relato dos bastidores dessa articulação está em nove páginas do Prólogo, a última parte escrita por Lira Neto na produção do livro. $\mathrm{O}$ jornalista optou por abrir a sua narrativa pelo mais recente acontecimento relacionado à história de vida do biografado: a decisão do Vaticano em rever o processo de excomunhão do padre nordestino visando à sua reabilitação e, posteriormente, à sua canonização. Seguindo a "lógica" jornalística, o biógrafo escolheu iniciar a narrativa pelo fato que faz a trajetória de vida do Pe. Cícero ser "noticiável" novamente, utilizando o critério de atualidade. Isso também justifica a escolha do Prólogo como objeto de análise neste texto: a produção dessa narrativa e a decisão de colocá-la na abertura do livro foi uma decisão de caráter jornalístico, tomada a partir do critério de noticiabilidade ${ }^{11}$, observando os valores-notícia interesse, atualidade e importância, que definem o "limiar noticiável" (Wolf apud Alsina, 2009, p. 154) do acontecimento.

Na primeira página da caderneta, o jornalista faz um esquema que intitula, primeiramente, de "apontamentos para o prólogo" e, logo abaixo, define o que será trabalhado: "que tratará do processo de reabilitação de Cícero Romão Batista". Na sequência das anotações, define qual será a "ação básica" - que deverá abrir o texto - e decide ambientar a ação no gabinete do cardeal Joseph Ratzinger, no Vaticano. Nesse "cenário", constrói o texto dos dois primeiros parágrafos como um narrador onisciente, um voyeur, descrevendo o início de um dia na vida do cardeal na "Primavera de 2001", sua rotina no Vaticano, seus pertences e seu local de trabalho até o momento em que este escreve o esboço da carta com os argumentos sobre a validade de uma reabilitação canônica do Padre Cícero. Para finalizar o segundo parágrafo, decide apresentar o seu personagem principal em um pequeno perfil, revelando a complexidade do biografado:

Um clérigo julgado e condenado como insubmisso, contra o qual os inquisidores da época decretaram a pena de excomunhão. Um reverendo maldito, que a despeito disso continua a arrebanhar milhões de peregrinos e devotos, incansáveis perpetuadores de sua memória: o padre Cícero Romão Batista (Lira Neto, 2009, p. 12).

Nas orientações de estilo ${ }^{12}$ pertinentes à construção narrativa, é importante observar algumas estratégias prévias do autor, para assim compreender como o jornalista constrói o seu relato. Para contar a história, Lira Neto empreendeu, além de uma grande investigação sobre a vida do personagem, uma ampla pesquisa sobre a cultura nordestina. Na região Nordeste do Brasil, a história do Padim Ciço, como é chamado por seus devotos, é contada em versos na literatura 
de cordel. Todos os principais momentos da vida do sacerdote têm registro nessa literatura popular muito tradicional naquela região do país, encontrada em folhetos que ficam pendurados em cordões e que são vendidos nas feiras, praças, bancas de jornais em cidades do interior e subúrbios. Visando estabelecer essa ligação entre o personagem e a cultura, Lira Neto utiliza a forma dos versos do cordel para fazer a titulação de cada um dos capítulos. No Prólogo, o autor começa dizendo: "Nos bastidores do Vaticano, o futuro papa Bento XVI planeja redimir um padre maldito" (Neto, 2009, p. 11). Esse tipo de estratégia revela o saber narrativo do jornalista, que caminha junto ao seu saber investigativo para a produção da reportagem. $\mathrm{O}$ recurso utilizado também pode ser classificado como um valornotícia "de construção, conferindo impacto às chamadas. Eles aparecem geralmente em títulos mais criativos do que informativos" (Moreira, 2006, p. 102).

Observa-se a partir do terceiro parágrafo que o autor sai do cenário do gabinete do cardeal Ratzinger e parte para a explicação do "fenômeno" Padim Ciço. Para isso, nas suas anotações na caderneta, lista uma série de pontos que se fazem imprescindíveis para a compreensão do que se tornou a mitologia em torno do padre: "romarias", "número de romeiros", "estátua", "fama de milagreiro". Os resultados desses apontamentos podem ser observados no terceiro parágrafo, onde Lira Neto usa dados objetivos para conferir credibilidade ao relato.

[...] cerca de 2,5 milhões de fiéis que acorrem todos os anos a Juazeiro do Norte, cidade localizada a 520 quilômetros de Fortaleza, no interior do Ceará. [...] Em Juazeiro, a multidão compacta paga promessas, acende velas, renova a fé, faz novos pedidos e invoca a proteção de seu guia espiritual. No topo da serra que avizinha acidade, foi erguida uma imagem gigantesca de padre Cícero, com 27 metros de altura, uma das dez maiores estátuas cristãs de concreto das Américas. Próximo à capela onde está enterrado corpo do reverendo, na chamada Casa dos Milagres, o testemunho das centenas de milhares de graças alcançadas arrebatam o olhar de quem chega à porta. São os chamados ex-votos: fotografias e esculturas de madeira, cera ou barro, que reproduzem partes do corpo humano (Lira Neto, 2009, p. 12).

Essa busca pela objetividade no relato aparece também no momento em que Lira Neto retoma o fato do envio da correspondência de Ratzinger para a Nunciatura Apostólica do Brasil, em que trata da possibilidade de uma reabilitação canônica, para contar o início da movimentação no país para que os interesses do Vaticano fossem atendidos. Na caderneta, o jornalista ordena os seguintes fatos: "1) Ratzinger manifesta ao secretario geral da CNBB interesse no assunto"; “2) chegada de Dom Panico ao Crato. Pouco depois obtém aval do cardeal e proclama carta pastoral de apoio a romarias"; "3) [Dom Panico] nomeia comissão de estudos que abre arquivos"; “4) enquanto comissão trabalha, Ratzinger é eleito papa. Os documentos tentam trazer à luz a verdadeira história de Cícero".

Os quatro fatos apontados pelo jornalista são narrados com vistas a revelar os bastidores da instituição da comissão de estudos para a revisão do processo de excomunhão e o apoio do Vaticano. A construção da história por trás de cada um desses episódios se dá principalmente a partir da consulta a documentos da Igreja no Ceará e a reportagens publicadas na imprensa local e nacional, além de entrevistas. A recomendação do cardeal Ratzinger e o apoio às romarias estão registrados em um trecho do Anátema ao Acolhimento Pastoral, em uma cópia colada na caderneta pelo biógrafo. Essas informações são ratificadas por um trecho de uma entrevista de Dom Panico ao site catolica.net, por uma parte da segunda carta pastoral escrita pelo bispo do Crato para os fiéis e, ainda, uma entrevista de Panico ao jornal Folha de São Paulo em 24 de abril de 2005. Todo o material está colado na caderneta. As reportagens na imprensa local sobre o assunto cópias acessadas na internet - estão divididas nesta pesquisa por datas de acordo com os assuntos retratados. Além disso, um documento intitulado "A Jornada para a Reabilitação", que narra todo o processo, com textos, fotos e documentos, como a carta de Dom Fernando Panico ao então papa Bento XVI, sobre a necessidade de se levar adiante o processo, apresenta-se como outra fonte para a configuração da narrativa. Na composição textual desses fatos, observam-se as estratégias comunicativas utilizadas pelo jornalista para a construção da narrativa, assim como a tendência do jornalista em buscar a objetivação do seu discurso para a produção do "efeito de real", utilizando para isso recursos referenciais como a citação de trechos da carta escrita por D. Panico ao papa Bento XVI para reforçar a necessidade de apoio do papa à reabilitação. 


\section{Considerações finais}

Os caminhos aqui percorridos para a reconstrução dos passos de Lira Neto na produção do Prólogo foram orientados pelos pressupostos teórico-metodológicos da Crítica Genética, em que a investigação a partir das anotações da caderneta norteou todo o trabalho posterior de análise dos manuscritos e do texto final, numa busca pela apreensão da escrita jornalística pelo seu devir produtivo. A escolha da metodologia poderá contribuir para o enriquecimento da pesquisa no jornalismo e para as experiências dos estudos genéticos em outros campos de conhecimento além da literatura. O objetivo da Crítica Genética não reside no próprio objeto, como já se disse, pois outros pesquisadores também utilizam manuscritos, cadernetas, anotações, mas na compreensão do processo de criação de uma obra. Daí a sua transdisciplinaridade enquanto saber, pois está aberta para a intersecção com outros campos para contribuir na revelação de um fazer, de um percurso criativo.

Como bem define Hay (1999), a exploração do universo das anotações de uma caderneta e dos manuscritos se transforma em uma experiência de "uma escrita vivida". A seguir essa experiência, "em todas as etapas da sua atividade: na espreita da observação, nas transformações da memória, na busca de sistemas de ficção e de figuração, acaba-se por percebê-la como uma forma de existência" (Hay, 1999, p. 18).

Pois é para compreender essa existência da escrita - e do processo de produção - que este artigo pretende compreender a Crítica Genética como uma metodologia produtiva para a os estudos sobre a produção do acontecimento jornalístico, tenha ele registro na forma de biografia ou de qualquer outro gênero dos gêneros, como a reportagem, por exemplo.

\section{REFERÊNCIAS}

ALMEIDA, Simão Farias. Livro-reportagem: um gênero de polêmica. Disponível em: <http://www.ufrr.br/component/ option.com>. Acesso em: 22 maio 2008.

ALSINA, Miquel R. A construção da notícia. Petrópolis: Vozes, 2009.

CHARAUDEAU, Patrick. Discurso das mídias. São Paulo: Contexto, 2007.

CHAPARRO, Manuel Carlos. Sotaques d'aquém e d'além mar: travessias para uma nova teoria dos gêneros jornalísticos. São Paulo: Summus, 2008.

FRANCISCATO, Carlos Eduardo. A fabricação do presente: como o jornalismo reformulou a experiência do tempo nas sociedades ocidentais. São Cristóvão: Editora UFS/Fundação Oviedo Teixeira, 2005.

GOBBI, Maria Cristina. Método biográfico. In: BARROS, Antonio; DUARTE, Jorge. Métodos e técnicas de pesquisa em comunicação. São Paulo: Atlas, 2005.

GRÉSSILON, Almuth. Elementos de Crítica Genética: ler os manuscritos modernos. Porto Alegre: Editora da UFRGS, 2007.

GUERRA, Josenildo. O percurso interpretativo da notícia: verdade e relevância como parâmetros de qualidade jornalística. São Cristóvão: Editora UFS; Aracaju: Fundação Oviêdo Teixeira, 2008.

HAY, Louis. A literatura dos escritores: questões de crítica genética. Belo Horizonte: Editora UFMG, 2007.

. A montante da escrita. Rio de Janeiro: Fundação Rui Barbosa, 1999.

LIMA, Edvaldo Pereira. Páginas ampliadas: o livro-reportagem como extensão do jornalismo e da literatura. Campinas: Editora da Unicamp, 1993.

LIRA NETO. Padre Cícero - poder, fé e guerra no sertão. São Paulo: Cia. das Letras, 2009.

MARQUES DE MELO, José Marques. A opinião no jornalismo brasileiro. Petrópolis: Vozes, 1994.

MOTTA, Marly Silva da. O relato biográfico como fonte para a história. Revista Vidya, Santa Maria, n. 34, 2000.

MOTTA, Luis Gonzaga. Análise pragmática da narrativa jornalística. In: LAGO, Cláudia e BENETTI, Márcia. Metodologia de Pesquisa em Jornalismo. Porto Alegre: Editora Vozes, 2008.

MOREIRA, Fabiane. Os valores-notícia no jornalismo impresso: análise das "características substantivas" das notícias nos jornais Folha de São Paulo, O Estado de São Paulo e O Globo. 2006. Dissertação (Mestrado em Comunicação e Informação). - PPGCOM/UFRGS, Porto Alegre, 2006.

MOUILLAUD, Maurice. A crítica do acontecimento ou o fato em questão. In: PORTO, Sérgio Dayrell (Org.). O jornal: da forma ao sentido. Brasília: Paralelo 15, 1997.

RODRIGUES, Adriano Duarte. O acontecimento. In: TRAQUINA, Nelson (Org.). Jornalismo: questões, teorias e “estórias". Lisboa: Veja, 1993.

SALLES, Cecília Almeida. Crítica genética: fundamentos dos estudos genéticos sobre o processo de criação artística. 3. ed. São Paulo: EDUC, 2008.

SODRÉ, Muniz. A narração do fato: notas para uma teoria do acontecimento. Petrópolis: Vozes, 2009.

VILAS BOAS, Sergio. Biografias e biógrafos: jornalismo sobre personagens. São Paulo: Summus, 2002.

\section{NOTAS}

1 Paper produzido no âmbito do projeto de pesquisa Tecer - Jornalismo e Acontecimento, financiado pelo edital PROCAD/CAPES.

2 Exemplo disso são as várias biografias existentes sobre personagens como Machado de Assis, Sigmund Freud, Madonna e Maysa, por exemplo.

3 A história de vida dá atenção total ou parcial às narrativas sobre a vida de indivíduos, mas visando humanizar um 
tema, um fato ou uma situação contemporânea. Já o perfil é uma narrativa mais curta, que tem por finalidade focalizar de forma breve alguns momentos da vida pessoal da personagem (Gobbi, 2005, p. 85)

4 Pela perspectiva estruturalista e totalizante da ciência historiográfica. Na medida em que privilegiava as análises de natureza econômica ou sociológica, parecia arbitrário, e mesmo perigoso, selecionar um indivíduo dentre os homens que fizeram e fazem a história. Mais grave ainda era admitir a possibilidade de que essa história de vida pudesse fornecer elementos de compreensão do todo social. Além disso, havia o risco de o historiador deixar-se envolver pelo biografado, o que lhe retiraria a capacidade crítica e o distanciamento indispensáveis ao ofício de pesquisador (Motta, 2000, p. 2).

5 Evolui do relato amplo com base no factual, predominante no século XVIII, passando pela hagiografia do século XIX, até encontrar-se com o romance moderno do século XX.

6 O autor classifica os livros-reportagem em várias outras modalidades: perfil, depoimento, retrato, ciência, ambiente, história, nova consciência, instantâneo, ensaio e viagem. Almeida (2008), por sua vez, propõe uma classificação mais concisa, e os divide em quatro tipos: biografia, tese, romance e factual.

7 Classificação de Marques de Melo (1994).

8 Classificação de Chaparro (2008).

9 Alguns autores, como Lima (1993), circunscrevem o livroreportagem ao conceito de jornalismo literário.

${ }^{10}$ Os estudos genéticos tiveram início na França, em 1968, quando, por iniciativa de Almuth Grésillon e Louis Hay, o Centre National de La Recherce Scientifique (CNRS) criou uma pequena equipe de pesquisadores, germanistas ou de origem alemã, para organizar os manuscritos do poeta alemão Heinrich Heine, que tinham acabado de chegar à Biblioteca Nacional da França. Depois de passar por diversas fases na França, a crítica genética difunde-se para outros países, inclusive o Brasil, onde foi introduzida por Philippe Willemart, e que sediou em 1985, na USP, o I Colóquio de Crítica Textual (Salles, 2008).

${ }^{11}$ Utiliza-se a concepção de Franciscato sobre noticiabilidade, que a apresenta a partir de "duas premissas: a de que é possível encontrar no evento noticioso características estáveis e recorrentes que revelariam sua especificidade; e que esses critérios são, de alguma forma, manuseáveis por jornalistas no seu cotidiano profissional, servindo concretamente como técnica ou recurso de trabalho" (Franciscato, 2005, p. 172).

${ }^{12}$ Nesta pesquisa, entende-se como orientação de estilo a definição de Bakhtin, utilizada por Ponte (2005). O autor explica que "o estilo de um discurso [...] está inseparavelmente ligado a unidades temáticas particulares e, sobretudo, a unidades particulares de composição: construções particulares do todo, tipos da sua constituição, tipos de relação entre o orador e os outros participantes (leitores ou ouvintes, parceiros, as suas falas e por aí adiante). Os estilos têm ainda o poder de circular de um gênero para outro, numa referência que, note-se, 'não só altera o modo como um estilo aparece nas condições de um gênero que não lhe é natural, como também viola ou renova o próprio gênero de origem'." (Bakhtin apud Ponte, 2005, p. 29). 